\title{
SOCIEDAD RACIONAL Y EDUCACIÓN: LA GÉNESIS DE LA RACIONALIDAD EDUCATIVA MODERNISTA
}

\author{
Guillermo Miranda Camacho ${ }^{1}$
}

\section{Resumen}

Este ensayo tiene por objeto explorar algunas dimensiones del origen y la génesis de la racionalidad educativa modemista. En esa dirección, el hilo conductor del análisis está centrado en examinar algunas dimensiones de la interacción dialéctica que históricamente se ha establecido entre la lógica racional de los cambios estructurales de la sociedad capitalista y la construcción de la concepción educativa modemista liberal. En la búsqueda de definir las claves de ese proceso, realizamos, en el primer apartado, una breve referencia a las bases de la emergencia del pensamiento racional y las bases de la modemidad que tuvo lugar a raíz del proceso de secularización del universo cultural renacentista. En la segunda parte, nos referimos a algunas dimensiones de la Ilustración y el enciclopedismo como proyectos culturales y educativos fundamentales para la organización racional de la sociedad en el siglo XVIII. En el tercer apartado, desarrollamos algunas dimensiones de la vinculación entre la modemización capitalista y la racionalidad educativa, recurriendo a algunos de sus principales factores históricos: la configuración del Estado-nación, la nacionalidad y la ciudadanía, la racionalidad del capitalismo liberal, la universalidad y el etnocentrismo de la cultura burguesa, la razón instrumental y la concepción del progreso como evolución técnica. Asimismo, destacamos la asunción de la educación por el Estado como parte de la conformación de la esfera de lo público y de su aparato, poniendo de relieve el papel racionalizador y legitimador que están en la base de estos procesos históricos. En el cuarto apartado, analizamos cómo la conformación de la racionalidad modemista adopta una visión historicista del progreso social que abandona la eticidad humanista. Proceso que incide en la emergencia de una racionalidad educativa basada en una justificación ideológica de la desigualdad y en una visión meritocrática en la sociedad racional, como la ha denominado Touraine (1993).

\footnotetext{
${ }_{1}$ Guillermo Miranda Camacho: Sociólogo, Doctor en Ciencias de la Educación. Profesor de la División de Educación Rural, CIDE Universidad Nacional. (gmic1@hotmail.com)
} 


\section{Abstract}

The objective of this article is to explore some aspects related to the origin of modern education rationality. The study is based on the analysis of different dimensions of the dialecticalinteraction historically established between the rational logic behind the structural changes of the capitalist society and the construction of the modern liberal education perspective. With the purpose of defining the keys to the process, the first section provides a brief reference to the foundations of the origin of rational thinking and those of modernity, which was caused by the secularization process suffered by the universe of the renaissance culture. In the second part we discuss some dimensions of illustrations and the encyclopedia as basic cultural and education projects in the rational organization of society in the XVIII century. The third section explores some dimensions of the connection between capitalist modernization and educational rationality through some of the main historical factors: the creation of State-nations, nationality and citizenship, the rationality of liberal capitalism, the universality and ethnocentrism of the elite culture, the instrumental reason and the view of progress as technical evolution. In addition, we highlight the State's adoption of education as part of the construction of the public sphere by emphasizing the rational and legitimating role that lies at the basis of these historical processes. Finally, the fourth section analyzes how the creation of modern rationality takes on a historical view of social progress neglecting humanistic ethics. This process influences the emergence of an educational rationality based on the ideological justification of inequality and on a meritocratic view of the rational society, as Touraine has defined it (1993).

Descriptores: educación, meritocracia, racionalismo, cambio estructural.

\section{EL PENSAMIENTO RACIONAL Y EL SURGIMIENTO DEL MO- DERNISMO}

$\mathrm{U}$

na de las más trascendentales herencias del Renacimiento fue el tránsito de la concepción medieval teocéntrica a una concepción antropocéntrica. Los argumentos metafísicos de corte místico-teológicos se sustituyen por razonamientos que conciben al individuo como el centro alrededor del cual se organiza todo, dotado de conciencia de sí mismo y del lugar que ocupa en el universo. Fue un periodo de transición en el que se desarrolla la trama del fin del periodo medieval europeo: de su sistema productivo, de sus instituciones políticas y sociales, de su Welstanchauung. La secularización devino en un medio para lograr la ruptura con las manifestaciones dominantes del orden teológico feudal, principalmente del sistema aristotélico-tomista. Si bien, en el Renacimiento no hubo un desprendimiento total con la concepción teocéntrica del 
catolicismo medieval, lo cierto es que, como tendencias predominantes, la concepción de la persona humana y las visiones de la naturaleza y de la sociedad se despojaron de la tutela religiosa. Este cambio en la visión del mundo influyó decididamente en el surgimiento del pensamiento racionalista; fue un proceso expansivo que abarcó un amplio espectro de dimensiones: la concepción del hombre, el conocimiento y la forma de adquirirlo, la noción del tiempo, la sociedad, el Estado, la economía, las instituciones y las principales expresiones culturales de esa época.

La invención de artefactos mecánicos, nuevos métodos de navegación y, sobre todo, de la imprenta amplían las posibilidades que propiciaron -como afirma Picó (1999) - la ampliación del panorama instrumental y el nuevo ethos del 'cultus vitae', con los cuales la humanidad accede a la naturaleza conociéndola y transformándola. La invención de la imprenta se constituyó en una de las contribuciones más decisivas en la ampliación de la difusión del conocimiento producido en esa época y del redescubrimiento de las obras clásicas de la antigüedad.

Al escrutarse el cosmos y la naturaleza se ensancha la visión del universo; el siglo XVI fue el escenario de una magna producción revolucionaria en el campo científico. En el campo de la astronomía la teoría heliocéntrica de Copémico, expuesta en su obra De Revolutionibus Orbium Caelestium (1543), supera el sistema geocéntrico de Tolomeo aceptado a lo largo de la Edad Media. Este revolucionario avance científico se complementó, a principios del siglo. XVII, con los posteriores aportes de Kepler con las leyes del movimiento planetario. Con esta nueva síntesis científica, se produce un cambio de visión, - una ampliación de horizontes, que modificó decididamente el sentido espaciotemporal de la vida individual, social y cultural en el escenario histórico ${ }^{2}$. Así, el cambio en la concepción y revalorización del tiempo influyó en el cambio de la visión del mundo y, en consecuencia, en la vida sociocultural (condicionando la emergencia de las nuevas relaciones sociales y prácticas sociales) y provoćando cambios en el proceso productivo. A guisa de ejemplo, la burguesía protestante suprime las festividades del catolicismo medieval para aumentar los días de trabajo, mientras la burguesía del capitalismo manufacturero apuraba el paso para ponerlo al ritmo de la producción. El aprendizaje de la nueva

\footnotetext{
2 El cambio del sentido espacio-temporal tiene una significativa importancia. porque sentará las bases de la futura concepción acerca de la relación entre tiempo y espacio en el curso de la modemidad. Giddens (1999) establece al respecto una conexión entre la modemidad y la transformación del tiempo y el espacio. Respecto del sentido del tiempo, Fernando Sabater (2001, p. 38) hace la interesante observación: "El tiempo es nuestro invento más característico, más determinante y también más intimidatorio: que todos los modelos simbólicos según los cuales organizan su vida los hombres en cualquier cultura sean indefectiblemente temporales, que no haya comunidad que no sepa del pasado y que no se proyecte hacia el futuro es quizá el rasgo menos animalesco que hay en nosotros".
} 
noción del tiempo fue recogido como parte fundamental en la nueva educación que propuso Comenio en su Didáctica Magna (1657), en la cual preconizaba, como parte de sus principios educativos, la necesidad del ahorro del tiempo (Ponce, 1987).

La observación directa de la naturaleza y la experimentación enriquecieron el avance de las ciencias: una nueva cultura científica se perfiló bajo la tutela de la razón. Galileo es un conspicuo ejemplo de ese revolucionario cambio; por ello se le ha considerado como el arquetipo del espíritu modernista de esa época, no sólo por su defensa de los postulados copernicanos, sentar las bases de la nueva mecánica y su paradigmática obra científica (fruto de la aplicación del método experimental), sino también por representar un símbolo de lucha y oposición al dogmatismo y la intolerancia religiosa de su tiempo. Los avances del conocimiento científico y de sus métodos ponen de relieve una revolución científica en el sentido y dimensión paradigmática que formuló Khun $(1986)^{3}$. Los aportes científicos de Galileo y Kepler inauguran una línea ascendente de avance científico que encuentra con Newton su momento culminante, con el desarrollo de una física general expuesta en su Principia (1787) y con el paradigma científico de la ley de la gravitación universal.

La liberación del principio de autoridad teológico acerca al hombre a la naturaleza, pero ya no en una actitud exclusivamente contemplativa, ese acercamiento se define ahora en la búsqueda de su conocimiento directo y su transformación. Esta posición pone de manifiesto la nueva filosofía de la naturaleza, basada en la creencia del determinismo de las leyes naturales, como relaciones necesarias que resultan de la naturaleza de las cosas y cuyo conocimiento es necesario para utilizarlas en provecho de la humanidad. La razón se constituye en la condición totalizadora y unificadora de la vida individual y de todas las esferas de la sociedad. Muchas manifestaciones del pensamiento que se gestaron en ese periodo estuvieron profundamente influidas por el pensamiento racionalista; entre ellas: la noción ontológica del ser (desde la doble dimensión de autonomía y libertad), la moral, la ética, las relaciones hombre/naturaleza, la visión de la historia y, las reflexiones acerca de la naturaleza de la relación sociedad/poder y muchas otras. La concepción del hombre que germinó en el Renacimiento (según la naturaleza y según la razón) liberada de las influencias de la escolástica medieval, servirá de fundamento epistemológico para todas

\footnotetext{
${ }^{3}$ Alan Chalmers (2000, pp. 111-112) puntualiza acerca del concepto kuhnniano de paradigma: "Un paradigma entraña un determinado marco conceptual a través del cual se ve el mundo y en el cual se le describe, y un determinado conjunto de técnicas experimentales y teóricas para hacer que el paradigma se compagine con la naturaleza". Más adelante concluye: "Cuando la falta de compaginación es seria, esto es, cuando se desarrolla una crisis, el paso revolucionario de reemplazar todo el paradigma por otro resulta esencial para el progreso efectivo de la ciencia".
} 
La observación directa de la

naturaleza y la experimentación

enriquecieron el avance de las

ciencias: una nueva cultura

científica se perfiló bajo la tutela de

la razón. Galileo es un conspicuo

ejemplo de ese revolucionario

cambio; por ello, se le ha

considerado como el arquetipo del

espíritu modernista de esa época,

no sólo por su defensa de los

postulados copernicanos, sentar

las bases de la nueva mecánica y

su paradigmática obra científica

(fruto de la aplicación del método

experimental), sino también por

representar un símbolo de lucha y

oposición al dogmatismo y la

intolerancia religiosa de su tiempo.

\section{, :}

desde una visión que supera las obras políticas antiguas que la elevaban a un sistema más general de problemas y la subordinaban al reduccionismo de soluciones religiosas, éticas o filosóficas (Cerroni, 1986). Con El Príncipe la secularización y el pragmatismo, como antítesis del pensamiento antiguo especulativo, se manifiesta en una lógica racional de análisis de la política como expresión de un mundo real. Respecto de esta obra, Gramsci (1975, p. 28) expresa que "Maquiavelo trata de cómo deber ser el Príncipe para conducir un pueblo a la fundación de un nuevo Estado y la investigación es llevada con rigor lógico y desapego científico. Su principal contribución consistió en considerar la política como objeto autónomo y su estudio como disciplina autónoma, con lo cual inaugura la ciencia política moderna y su núcleo esencial: la teoría del Estado. 
Algunas obras representativas de la ruptura intelectual con los principios de conocimiento vigentes adquirieron un carácter emblemático. Una de ellas fue el Novum Organum Scientiarum de Bacon ${ }^{4}$ (1620) que representa el momento histórico de la formulación lógica del moderno método científico. Con su rechazo de la lógica deductiva como instrumento de descubrimiento y la formulación explícita y sistemática de la inducción experimental, como instrumento para la manipulación y ordenación de los hechos, desarrolla una teoría de la experiencia (De Gortari, 1971). La apreciación de Bacon respecto de la aplicación práctica del conocimiento, expresada en su célebre frase: Knowledge is power, exalta con visión futurista el valor utilitario de la ciencia y la concepción empirista del conocimiento. Descartes, por su parte, expuso el método científico después de utilizarlo en la fundación de la nueva ciencia de la geometría analítica, y como prueba demostrativa propuso la duda metódica en su Discurso del método (1637). En el campo pedagógico condenaba los programas y procedimientos de la antigua educación y preconizaba que en las escuelas la enseñanza se deslindara de la filosofía especulativa y adoptara una filosofía práctica, que partiera del conocimiento de la naturaleza, de la misma forma en que los artesanos conocían su oficio.

El movimiento pedagógico que se inicia en el Renacimiento se gestó y creció vigorosamente bajo el influjo de la divulgación de obras fundamentales de corte humanístico que dieron una brillante contribución a la revolución cultural que tuvo lugar en esa época. Figuras como Erasmo, Rabelais, Montaigne, y por su puesto Comenio, brindaron aportaciones decisivas en la evolución moderna del pensamiento pedagógico y difundieron sus aportes en un ambiente cultural que crecía mostrando sus fecundos frutos. Con la publicación de la Didáctica Magna (1657) de Comenio -considerado como el primer gran pedagogo de la Época Moderna- se avizora la nueva tendencia de cambio educativo en los albores de la modernidad. Su intención de replantearse la práctica pedagógica, abandonando los "libros muertos" para abrir "el libro vivo de la naturaleza", es decir, formar a la juventud enfrentándola a "las cosas mismas", puso de relieve la naturaleza de ese cambio: la adecuación de la escuela a las aspiraciones tanto de la burguesía emergente (que se consolidaba cada vez más), como a la demanda de los talleres artesanales de la pequeña burguesía. Acerca del significado histórico del pensamiento educativo de Comenio, Jean Piaget expresa:

Comenio es considerado como un gran precursor de los designios contemporáneos de colaboración intemacional sobre el terreno de la educación,

\footnotetext{
$\overline{4}$ Bacon manifestó una excelente valoración de El Príncipe de Maquiavelo por el método de análisis utilizado.
} 
de la ciencia y de la cultura. Al escribir su Didáctica Magna, Comenio contribuyó a crear una ciencia de la educación y una técnica de la enseñanza, como disciplinas autónomas. Comenio es de esos autores que no es necesario corregir para modernizarlos, sino que basta solamente con traducirlos. (Citado por Fernández Enguita, 198, p. 23, en la Introducción de la Didáctica Magna de Comenio).

La educación recibió tres grandes impulsos de dimensión histórica en los albores de la Edad Moderna, apunta Mariano Fernández Enguita (1986). El primero fue la herencia del Renacimiento, con su prolongación en el humanismo. El segundo impulso fue la Reforma protestante. Y el tercero, la Contrarreforma católica en la cual los jesuitas emplearon como medio de acción privilegiado la enseñanza. "Se puede discutir hasta qué punto se prefigura entonces la escuela actual, pero está fuera de dudas -afirma Fernández (1986, p. 8) que surge o se consolida en buena proporción el que todavía hoy es el discurso dominante en materia de educación". Aunque este autor relativiza la importancia de la educación en este periodo, reconoce que en el conjunto de su legado histórico se le debe la recuperación de una idea de una formación humana integral y la revalorización del saber. En lo que respecta a esta segunda contribución, subraya un hecho de singular importancia, para el ulterior proceso de modernización de la formación social capitalista: el paralelismo, que une el Renacimiento al dinero y el conocimiento, como factores capaces de legitimar una visión meritocrática de la sociedad opuesta a la antigua concepción del orden estamental (Fernández, 1985). El ulterior curso evolutivo de esta visión meritocrática de la vida social y el papel del sistema educativo tendente a reforzar y justificarla, como lo analizaremos más adelante, se constituirá en una conspicua expresión histórica de la sociedad racional.

Así pues, el alejamiento de toda imposición teológica abrió nuevos espacios para la ciencia y la razón que devinieron en fundamentos básicos de la idea de progreso. Los cambios estructurales de la incipiente formación social capitalista asegurarán la ideología del progreso a su base material. Con esta nueva visión del mundo, el progreso material y social se convierten en una aspiración esencial en la naciente sociedad capitalista y, al mismo tiempo, en la visión que preconizará la intelligentsia de este periodo.

Se inicia así, el proceso de avance de las ciencias positivas y, a su privilegiada valoración, se adhiere la concepción histórica de progreso por el cual la humanidad seguirá una trayectoria ascendente hacia estadios superiores de vida social bajo el dictado de la razón y la fe suprema en el intelecto humano. Esta visión se apoyó, como hemos visto, en los postulados epistemológicos de la 
posibilidad del conocimiento directo, es decir, el conocimiento empírico de la realidad y su trascendencia para alcanzar el dominio de la naturaleza. Ya a finales del siglo XVII, John Locke, en su Ensayo sobre el entendimiento humano (1689-1690), postula consciente y sistemáticamente los problemas teóricos del conocimiento. La certeza del conocimiento y las posibilidades de extensión del conocimiento humano adquieren con Locke una dimensión de autonomía plena al reconocer como la fuente principal del conocimiento la experiencia (interior o exterior), con lo cual emerge la teoría empirista del conocimiento. Como observa Moya (1975, p. 40), esta visión epistemológica basa "la reducción de la realidad a pura espacio temporalidad, objeto de observación, experimentación y organización técnica" con lo cual funda las bases de un dominio "racional" del mundo. Fue éste el resultado histórico de la pérdida de los vínculos religiosos, de la secularización de la visión del mundo, que permeó la cultura del capitalismo tanto en su marco axiológico como en sus formas, que sustentó la nueva moral universal y en el que se erigen los fundamentos de la organización económica, social, política y cultural de la sociedad capitalista.

En este contexto histórico, la revolución pedagógica surgió como una respuesta fundamental ante la obsolescencia del sistema antiguo y la necesidad de adaptarlo a la nueva organización social emergente. A la idea de progreso, estarán indisolublemente asociadas concepciones y tendencias que, a modo de motivos guías, serán temas constantes y definitorios del pensamiento modernista en el curso de su evolución, entre los cuales cabe destacar:

- $\quad$ El humanismo secular, cuyo principio ontológico defiende la naturaleza racional del ser humano y la consiguiente autonomización de la razón, sirvieron de pilares al desarrollo individual y a la autodeterminación colectiva de la sociedad.

- La emergencia de la noción de modernismo con su complejidad teórica, ideológica y política que abarca tres tradiciones: la social, la estética y la política. $1^{\circ}$ ) En lo social, está representada por los cambios de la organización económico y social que surge bajo el influjo del desarrollo de las relaciones de producción capitalista (idea burguesa de modernidad); que a su vez origina la doctrina del progreso que descansa en las inconmensurables posibilidades de la ciencia y la tecnología, y la nueva revalorización del tiempo (que adquiere un valor económico, una suerte de cuasimercancía). $2^{\circ}$ ) En lo estético, se manifiesta en las tradiciones de resistencia y esteticismo formal, que a su vez, tiene su contrapartida en una tendencia adversa a los valores burgueses, que se manifiesta en movimientos literarios y de vanguardia que conciben el arte como una representación 
de la crítica, la rebelión y la resistencia. $3^{\circ}$ ) El modernismo político construye su ideario en el contexto de la Ilustración y origina dos doctrinas: el liberalismo económico y el liberalismo político. La primera identifica la libertad con la dinámica del mercado capitalista; la segunda, asocia la libertad con los principios y derechos que emanaron de la revolución democrática liberal del mundo occidental (Giroux, 1997, p. 64).

- El surgimiento del liberalismo, como cuerpo doctrinal político, social, económico y cultural que exalta, naturaliza, racionaliza, legitima y, sobre todo, universaliza los valores de la cultura hegemónica burguesa y la democracia liberal, constituirá el ideario político de la Revolución Francesa y de los procesos independentistas de los Estados Unidos y los países de América Latina.

- La búsqueda de una moral universal inspirada en el principio de la bondad natural del hombre, pero que al mismo tiempo reconoce como naturales las diferencias sociales, servirá de fundamento a la emergencia de las teorías sociales funcionalistas-meritocráticas.

- La visión y organización racional de la sociedad, fundamento ideológico que, al tiempo que se origina con el surgimiento de la estructura de producción capitalista, influirá decididamente en la configuración modernista de las formaciones sociales capitalistas y en la estructuración del Estado-nación (principio que será incorporado, en el origen y desarrollo de las ciencias sociales, como principio epistemológico de las corrientes teóricas positivistas).

Este proceso, sobre el que hemos resaltado apenas algunos de sus rasgos más notables, se desarrolló en el marco de la expansión mercantil que da origen, a partir del siglo XVI, al ciclo histórico de acumulación capitalista en la forma mercantilista. Momento histórico anterior a "la revolución industrial y moldeado por la hegemonía del capital mercantil en los centros atlánticos dominantes, así como la creación de zonas periféricas (América) cuya función presuponía su total aceptación de la lógica de acumulación del capital " (Amín, 1999, p. 15). La tendencia a universalizar la cultura burguesa del capitalismo surgió desde el mismo origen de la modernidad, como una dimensión básica de ese proceso estructural y se pondrá de manifiesto en el curso de su génesis y consolidación.

\section{RAZÓN ILUSTRADA Y EDUCACIÓN}

Es en el Siglo de las Luces cuando tendrá lugar el movimiento de la Ilustración y bajo su influjo, la consolidación del ethos racionalista. El espíritu 
antiteológico y antieclesiástico será la tónica fundamental de este periodo en el cual prolifera el rechazo a las controversias sobre la concepción teocéntrica de la escolástica medieval y se rechaza la autoridad de la Iglesia tanto en el plano espiritual como en el terrenal. Aunque persistan ciertas manifestaciones deistas (como Voltaire, Rousseau); sin embargo, será el laicismo quien asuma un papel protagónico en la entronización social de la razón humana. Como movimiento cultural fecundo en la producción de pensamiento y como concepción filosófi$\mathrm{ca}^{5}$, la Ilustración asegurará y profundizará el pensamiento racional ampliando su esfera de investigación y aplicación en todos los ámbitos del conocimiento acerca de la realidad. Así pues, la filosofía abandona el predominante carácter especulativo que la confinaba a una estructura doctrinal particular y deviene en un medio universal en el cual las ciencias naturales, la historia, la política y el derecho encuentran su espacio de enriquecimiento y avance. La fuente de donde emana el verdadero significado del conocimiento y, por lo tanto, de la verdad es la razón humana concebida como una razón universal basada en el sistema lógico de la misma naturaleza. Este es quizá el principal legado del Siglo XVIII.

La revolución intelectual que tenía lugar en esta época se manifestó en la variada y fecunda obra intelectual de los filósofos ilustrados y en la monumental producción científico-técnica, que definía los contomos de la modemidad. El principal significado de la Ilustración, desde una visión histórico social, consiste en que en ese periodo se construye el proyecto de la modemidad. Sobre este asunto, Jürgen Habermas (1998, p. 28) expresa:

El proyecto de la modernidad formulado en el siglo XVIII por los filósofos de la Ilustración consistió en sus esfuerzos para desarrollar una ciencia objetiva, una moralidad y leyes universales y un arte autónomo acorde con su lógica interna. Al mismo tiempo, ese proyecto pretendía liberar los potenciales cognoscitivos de cada uno de estos dominios de sus formas esotéricas. Los filósofos de la Ilustración querían utilizar esta acumulación de cultura especializada para enriquecimiento de la vida cotidiana, es decir, para la organización racional de la vida social cotidiana.

Es el momento de la euforia racionalista que lleva a Condorcet en su obra Bosquejo de un cuadro histórico de los progresos del espíritu humano (1794) a

\footnotetext{
${ }^{5}$ Utilizamos la nación de filosofía en el sentido que le otorgó Gramsci, quien le confiere el lugar más elevado entre los distintos grados cualitativos de la ideología. En referencia a la noción gramsciana de esta categoría Portelli (1977, p. 20) observa: "La filosofía es entonces el estadio más elaborado de la concepción del mundo, el nivel donde más claramente aparecen las características de la ideología como expresión cultural de la clase fundamental". Asimismo, destaca dos aspectos esenciales: la filosofía es la referencia básica de todo el sistema y le da coherencia, contribuyendo además a conservar la "unidad ideológica de todo el bloque social que precisamente es cimentado y unificado por esta ideología" (Portelli, 1977, p. 58).
} 
exaltar el triunfalismo de la razón. El modernismo es la expresión de la civilización que eleva a un rango ideológico superior la racionalidad de la vida social y económica. En efecto, la exaltación de la razón como ideal humano, y, por lo tanto, ideal educativo, alcanzó dimensiones inusitadas al punto que se llegó a asumir que la condición esencial del hombre en el medio social y su valoración moral tenían como condición esencial la razón. En el siguiente pasaje de la Ética (1675), Spinoza expresa nítidamente esta visión:

Nada puede concordar mejor con la naturaleza de una cosa que los demás individuos de su especie; por tanto, nada hay que sea más útil al hombre, en orden a la conservación de su ser y el disfrute de una vida racional, que un hombre que se guíe por la razón. Además, dado que entre las cosas singulares no conocemos nada más excelente que un hombre guiado por la razón, nadie puede probar cuánto vale su habilidad y talento mejor que educando a los hombres de tal modo que acaben por vivir el propio imperio de la razón (Citado en Sabater, 2001, p. 198; el destacado es nuestro).

En un contexto de cambio estructural profundo de la sociedad capitalista, la razón ilustrada abarcó, con amplitud totalizadora la vida cultural y política europea del siglo XVIII, manifestándose como una reacción crítica que el espíritu de las luces emprendió contra la religión, la tradición y el autoritarismo político. Eagleton (1997, pp. 94-95), observa que la oposición a la religión, a la tradición y a la autoridad política formó parte de las aspiraciones del pensamiento ilustrado que apelaban a una naturaleza desinteresada de la ciencia y la razón; sin embargo, señala que esas mismas aspiraciones escondían los intereses de poder a los que servían en secreto. Por otra parte, sitúa el papel de la educación en este periodo, poniendo de relieve que la finalidad de los ideólogos de la ilustración, como representantes de la burguesía del siglo XVIII, consistía en reconstruir la sociedad desde sus fundamentos sobre una base racional. Por lo cual arremetieron contra un orden social que reforzaba el poder absolutista brutal y fomentaba la superstición religiosa en el pueblo, soñando en un futuro en el que se honrase la dignidad de hombres y mujeres incapaces de sobrellevar falsas representaciones y falsas ilusiones. Esa base racional constituyó el fundamento del proyecto social y político, por el que luchaban los filósofos ilustrados. La posición de los ideólogos de la Ilustración era respaldada por la firme creencia en la fuerza de la educación; su creencia consistía en que al someter las leyes de la conciencia humana a inspección científica, esa conciencia se transformaría en la dirección de la felicidad humana mediante un 
proyecto pedagógico sistemático. De esta manera, el pensamiento ilustrado, la educación redefine su función ideológica, ante la necesidad de la burguesía ascendente de establecer bases racionales de estructuración social, acordes con la racionalidad de sus intereses hegemónicos económicos, políticos y culturales.

A pesar de las diferencias que existían acerca de un ideal de sociedad presentes en todo el espectro de ideas sociales y políticas que se produjeron en este periodo, esas distintas concepciones tenían como elemento indistinto y común la fe en la razón, como condición básica de toda forma de organización social. Además, como hemos visto, la construcción de la sociedad desde una base racional estaba condicionada por un acelerado momento de desarrollo de las ciencias, sus métodos específicos y las innovaciones tecnológicas que modificaban substantivamente las nuevas condiciones de la vida social (las formas de organización de la producción, los tipos de relaciones sociales, su estructuración, las prácticas sociales, el entorno cultural, y otras más). Ciertamente, el horizonte cultural de esta época se caracterizará por la búsqueda de racionalizar la vida social y, por ende, estará profundamente influida por la tendencia predominante de sistematizar y organizar la profusa producción de conocimiento producido en esa época que se divulgó en las grandes enciclopedias. El enciclopedismo nace, según Manacorda (1987), como una necesidad de búsqueda de reclasificación y modernización del conocimiento acumulado en el siglo XVII y a principios del XVIII (desde Bacon y Comenio hasta Leibniz). La proliferación de las artes y oficios se colocan en una posición de dignidad en la formación y la actividad del hombre a la par de las artes liberales, de la gramática y de la filosofía. El aporte innovador de los filósofos de la Ilustración --en su condición de intelligentsia de ese periodo- consistió no sólo en la sistematización del saber científico acumulado históricamente, sino, además, en intentar enriquecerlo y hacerlo avanzar.

La publicación de la Enciclopedia de las ciencias, de las artes y de los oficios (1751-1765), nació como una necesidad de reclasificación y modernización del saber acumulado en los siglos XVII y XVIII. Su significado histórico social consiste en que, en paralelo, conllevó un cambio de rumbo en la historia de la cultura, al introducir una dimensión nueva: la integración de las artes y los oficios a las ciencias y la cultura intelectual. El significado social de la Enciclopedia fue el de representar un proyecto pedagógico-cultural para la reconstrucción social, a partir de la racionalización. En lo social, reintegró a los artesanos y los productores; asimismo, exaltó las profesiones y el desarrollo industrial, tecnológico y las innovaciones agrícolas. Uno de sus aportes más significativos fue el de plantear la vinculación de la educación con la tecnología y 
su evolución a partir de la interrelación entre las "artes mecánicas a las ciencias puras". Con ello, quedó definida simultáneamente la relación entre la calificación de la fuerza de trabajo, la utilización racional del trabajo y la educación, así como los aspectos relativos al avance de la composición técnica y orgánica del capital, centrales en el proceso de cambio estructural económico que caracterizó la modernización capitalista.

Respecto del significado histórico de la Enciclopedia, Touraine (1993, pp. 24-25) observa que la idea de modernidad se asocia al proceso de racionalización y, por tanto, vincula históricamente las concepciones de modemidad y modernización a la creación de la sociedad racional en la que la razón ya no sólo está relacionada con la actividad científica y técnica, sino también con el gobierno de los hombres y la administración de las cosas. En consecuencia, pone de relieve que la racionalización es el principio único de organización de la vida personal y colectiva, y se asocia al tema de la secularización como "alejamiento de toda definición de los fines últimos". Con base en esto, aclara que el mundo occidental ha vivido y pensado la modemidad como una revolución en la cual la razón hizo tabla rasa de las creencias y formas de organización sociales y políticas que se funden en demostraciones de tipo científico. En cuanto a modemización, como hemos visto, la ruptura con las ataduras individuales, sociales y culturales tradicionales elevó a la razón a un primer plano, ante las exigencias crecientes del cambio que la modemidad imponía. De esta manera, se puso de manifiesto la indisolubilidad del nexo entre racionalidad/modernización/modemidad: la racionalidad es un mecanismo "espontáneo y necesario" de la modernización y, por ende, es un componente esencial de la modernidad. Por consiguiente, la modernidad es obra de la razón, vale decir, de la ciencia, la tecnología y la educación:

Lo que es válido para la sociedad, lo es para el individuo. Su educación debe ser una disciplina que lo libere de la visión estrecha, irracional, que le imponen su familia y sus propias pasiones, y obra del conocimiento racional y de la participación en una sociedad que organiza la acción de la razón. La escuela debe constituir un lugar de ruptura con el medio de origen y de apertura al progreso, a un tiempo por el conocimiento y por la participación en una sociedad fundada sobre principios racionales (Touraine, 1993, p. 27; el destacado es nuestro).

Esta concepción educativa adquiere una magnitud global en el contexto del desarrollo de la idea de modemidad y, desde un punto de vista sociogenético, se vincula en su significación histórica a los conceptos de cultura y civilización. La 
cultura llega a representar el carácter distintivo de la especie humana: es la suma de saberes acumulados y transmitidos por la humanidad, en consecuencia, su significado quedará asociado con las nociones de progreso, evolución y educación (Picó, 1999). Siendo producto de la separación entre la filosofía y la teología, la civilización se manifiesta como un ideal de perfectibilidad de la humanidad, de su explicación del mundo; la historia deviene, así, en una idea que sintetiza unitariamente la secularización del progreso. De hecho, la secularización de la cultura y su consecuente universalización no se circunscribieron a los límites del espacio geográfico de Europa, sino que se articuló a los procesos de expansión del capitalismo y la universalización de la cultura burguesa propia de la modernidad.

El trasfondo ideológico y político del enciclopedismo se manifiesta en el ámbito de la relación entre conocimiento legítimo y poder, es decir, la búsqueda de establecer un sistema hegemónico político-cultural que universalice la visión del mundo de los frutos más acabados productos de la secularización de la vida cultural. El carácter revolucionario de este cambio sociocultural estableció un hito histórico que afectó las distintas concepciones de cultura y los diferentes grados de poder en la génesis de la modernización de la sociedad racional. Apple (1996) explica que los libros y el saber leer en este periodo fueron objeto de la política cultural. En perspectiva histórica, el impacto de esta política cultural generó dos posiciones antagónicas en la relación entre los libros: la cultura escolar y el movimiento popular. Por un lado, la de la élite intelectual: los intelectuales orgánicos de la Ilustración y representantes de la nobleza, el grupo social ultraconservador, como fue el caso de Voltaire.

Para él, la Ilustración -comenta Apple (1996, p. 71)-debía comenzar con los 'grandes'; y que sólo cuando hubiera cautivado el espíritu y el corazón de la cumbre que domina la sociedad, podría interesarse por las masas de abajo. Pero Voltaire y muchos de sus seguidores había que tomar una seria precaución: Había que prevenir que las masas aprendieran a leer.

Otros intelectuales, asumiendo una posición conservadora más "moderada" en materia cultural, consideraban que enseñar a las masas podría tener más bien un efecto benéfico e iniciaría un proceso civilizador, en que los grupos subordinados se harían más morales y más obedientes asimilando la auténtica cultura $^{6}$. Por otro lado, estaban aquellos que veían en la utilización de los textos y la

\footnotetext{
${ }^{6}$ Apple identifica este proceso como la raíz histórica de lo que acontece actualmente con el neoconservadurismo educativo, en referencia a este proceso observa: "Por supuesto, hoy podemos escuchar ecos de esto en los argumentos de los conservadores en materia cultural" (Apple, 1996, p. 71).
} 
alfabetización un medio de promover transformaciones sociales dirigidas hacia la democratización de la cultura, de la economía y de la política.

Como una especie de onda expansiva, la universalidad modernista llevó al mundo periférico sus nociones de progreso y civilización, pero en lo que convenía a los propósitos hegemónicos del expansionismo colonial. Este momento histórico, Samir Amín (1999) lo distingue como el modelo clásico surgido de la Revolución Industrial, es decir, cuando se establecieron las formas básicas del capitalismo y a su dinámica se unieron las periferias y provocaron una polarización simultánea de dos procesos: el establecimiento de los sistemas industriales autocentrados y la construcción de los Estados-nacionales burgueses $^{7}$. La burguesía nacional legitimó y racionalizó sus valores e intereses particulares, universalizando el concepto de civilización europeo en torno al liberalismo político y económico. Eagleton (1997, p. 84) afirma que la ideología obtiene legitimidad utilizando el recurso de universalizarse o eternizarse; con lo cual "los valores e intereses que de hecho son específicos a una cierta época y lugar que se proyectan como valores e intereses de toda la humanidad". Los valores universalistas que preconizaba la burguesía fueron difundidos con arreglo a los intereses de "la lógica de la distinción centro/periferia inherente a la expansión mundial del capitalismo" (Amín, 1999, p. 105). Con este proceso, se difundió el carácter selectivo y discriminatorio de esos valores, y su visión etnocentrista, en el proceso colonial de dominación cultural y transculturación en las regiones coloniales periféricas del planeta.

\section{LA SOCIEDAD RACIONAL Y LA GÉNESIS DE LA MODER- NIDAD}

Los principales procesos y concreciones históricas de la sociedad racional que estuvieron estrechamente vinculadas a la conformación del proceso hegemónico educativo, esto es, del papel de la educación en la articulación del sistema hegemónico que impuso la burguesía emergente en la sociedad capitalista moderna, fueron: la demanda de liberación para las actividades económicas (despojadas del control y regulación del Estado absolutista) que plantean nuevas exigencias marcadas por la industrialización y profundizan la racionalidad economicista, la entronización de la ideología liberal (como doctrina

\footnotetext{
${ }^{7}$ Al referirse a este proceso Arnín (1999, p. 101 ) puntualiza que en "la época moderna, la revolución burguesa inició una segunda ola evolutiva que profundizó ý enriqueció el concepto de 'universalidad'". Y continúa: "De hecho, la filosofía de la Ilustración supuso el inicio de un movimiento que culminó en la revolución francesa. En lo relativo al concepto de nación, ésta definióun nuevo contenido, radicalmente diferente de aquél que habian experimentado sus vidas, su pertenencia a una comunidad o su percepción del universalismo y sus límites los miembros de las comunidades tributarias (la cristiandad, el mundo hindú o el mundo confuciano)" (Amín, 1999. p. 101)
} 
económica-política) y otras manifestaciones en las esferas sociopolítica y cultural, la formación de la nación asociada con la idea de progreso, el surgimiento del Estado nacional y el de ciudadanía, la exigencia de la autodeterminación como contrapartida de los modelos autoritarias del antiguo régimen, la consolidación de la sociedad civil, la expansión colonial con su concomitante universalización de la visión etnocentrista europea, la sacralización de la razón científica y la razón instrumental. Estos procesos han devenido en constantes históricas en el desenvolvimiento de modemización del sistema capitalista hasta nuestros días.

\section{Racionalidad económica y política del capitalismo liberal}

El conjunto de transformaciones que ocurren a partir del siglo XVIII definió más claramente los contomos a partir de los cuales se realizará el ulterior desarrollo histórico de la formación social y económica capitalista. Su configuración anunciaba, con los cambios en la estructura social y política y en el sistema económico, la Revolución Industrial y, por consiguiente, los cambios estructurales en todas las esferas de la sociedad global que iniciarían un estadio superior de avance del capitalismo. En la complejidad creciente de su organización racional, la formación capitalista ya exhibía a estas alturas los productos históricos frutos del progreso y, por lo tanto, de la modemización. Es en el último siglo de la fase previa a la Revolución Industrial (de la hegemonía del capital mercantil en los centros dominantes y del proceso de acumulación capitalista en los centros periféricos), cuando se muestran los gérmenes maduros del futuro mercado capitalista, de su estructura social de acumulación y de la organización racional superior del poder político, el Estado modemo.

En el plano de las ideas, fue el periodo en que aparece el liberalismo (como filosofía en el sentido gramsciano), uno de los corpus teóricos y doctrinales destinados a ejercer una de las mayores influencias en la conformación y ulterior desenvolvimiento de la sociedad modema en todas sus dimensiones ${ }^{8}$. Si bien las raíces del liberalismo se extienden hasta el mismo periodo de construcción del pensamiento racional (en el que se encuentran muchos de sus principios filosóficos), no será hasta el siglo XVIII cuando se manifiesta claramente en el pensamiento social y político de los filósofos de la Ilustración y en las

\footnotetext{
${ }^{8}$ López (1977, pp. 16-17) afirma: "El liberalismo fue la ideología de la sociedad capitalista; defendió, por tanto, un universo de valores que devolvía al individuo su supremacía en el seno de la naturaleza y de la sociedad. Esta, que no es sino el asiento natural del individuo, debería respetar simplemente el libre hallazgo del individuo por sí mismo. Obstaculizar el libre desarrollo del hombre en tanto que individuo, era, para el liberalismo, paralizar el proceso entero de la 'libertad'. La libertad era el individuo, y el individuo la propiedad."
} 
doctrinas económicas del laissez faire, laissez passer, defensoras de la libertad individual de iniciativa privada motivada por el afán de lucro, la libre competencia (como ente regulador de la producción y los precios) y las leyes económicas naturales de la oferta y la demanda. Doctrinas magistralmente expuestas por Adam Smith en su celebérrima obra conocida como La riqueza de las naciones (1776). Obra señera del pensamiento económico liberal que como lo ha manifestado Laski (1974, p. 153): "Trata de introducir orden en el caos, hacer patentes al hombre culto los principios adquisitivos de la riqueza. ¿Cuáles son las notas salientes del libro? Es secular en el tono, racionalista en el método e individualista en la visión".

El liberalismo económico encontrará, principalmente en la teoría económica de Adam Smith, el principal punto de apoyo para la defensa de la "ideología del mercado". El acercamiento al conocimiento de la realidad económica le permitió “descubrir" las leyes orgánicas y funcionales del capitalismo, que operaban y se desarrollaban en virtud de su propia condición natural y su propia existencia. La racionalidad económica del liberalismo devino en racionalización ideológica erigiéndose en un bastión de la defensa del liberalismo capitalista burgués (incluso en su versión del neoliberalismo actual). Ciertamente, el liberalismo como pensamiento burgués elevará la racionalidad económica como un valor absoluto y legitimador de la nueva organización social emergente, por lo que desde su origen se le otorga el carácter de un constructo eterno, que al sustituir a Dios por el Progreso (así, puesto con mayúscula), se convierte en la base de un orden etemo (Amín, 1999). Esta aguda observación del carácter que asume el liberalismo como ideología, vale decir, como cosmovisión de la burguesía sustentadora de un orden eterno, tiene cierta coincidencia con la visión de Schumpeter quien le confirió la cualidad esencial de ser un fenómeno evolutivo que poseía una inherente capacidad de autotransformación, por la cual revolucionaba incesantemente su estructura económica.

Ambas posiciones, a las que hemos recurrido como ejemplo, ponen de relieve la lógica argumental de las doctrinas económicas, sociales y políticas que llevan al extremo la justificación racional de la inmanencia del liberalismo, desde la visión de la realidad manejada por leyes naturales y, por lo tanto, objetivas. Pero también, la racionalización política y cultural de su visión del mundo que se construye y reconstruye para asegurar su sentido de realidad inexorable. Como bien lo afirma Ponce (1987, p. 134): "Tan pronto como la burguesía consiguió triunfar, pudo verse en efecto que la 'humanidad'y la 'razón' de que tanto había alardeado, no eran más que la humanidad y la razón 'burguesas"”. Esta visión se ha constituido, históricamente, en una constante ideológica, que ha acompañado la racionalidad y la racionalización del liberalismo en toda su 
génesis y consolidación hasta el día de hoy ${ }^{9}$. La tesis de la economía clásica, encontrará, asimismo, un complemento ideológico fundamental en el pensamiento darwinista social de Herbert Spencer y su defensa del individualismo (que evolucionará hasta su máxima expresión actual del individualismo posesivo), que apoyará y reforzará el pensamiento liberal, su principio de libre competencia y su credo individualista. Existe una coincidencia y convergencia en los supuestos y premisas sobre los que se edificará el edificio teórico clásico de la economía política de Smith (y David Ricardo), en los aspectos relativos a las leyes que rigen la dinámica del mercado capitalista para sobrevivir a sus condiciones. En una obra sobre educación, Spencer afirmaba, desde su óptica darwinista de lo social, la justificación para privar de la educación a la mayoría y su despreocupación por el problema de la educación popular y universal (Fernández, 1985). Pero, más aún, sostuvo la tesis de que el Estado no debe administrar la educación: "No puede mostrarse ningún motivo para tal interposición (la del Estado) -expresó- a menos que los derechos de los niños hayan sido violados, y sus derechos no son violados porque se descuide la educación" (Spencer, citado por Fernández, 1985, p. 39).

Otra dimensión del liberalismo es el referido a la relación entre Estado/ individuo. A este respecto, Matteucci (1983, pp. 908-909) explica que esta relación se planteó inicialmente a partir del concepto de individualismo, que sustentaron el iluminismo francés y el utilitarismo inglés. La acepción que defendían ambas corrientes de pensamiento partía básicamente de la defensa radical del individuo, como protagonista exclusivo de la vida ética y económica, contra el Estado y la sociedad, pero además de la oposición a la existencia de cualquier instancia intermedia entre aquel y el Estado. De esta manera, el individuo debía actuar por sí solo tanto en el mercado político como en el económico. El principal punto de controversia acerca de esta concepción, tuvo como referente común la sociedad civil: el espacio del ejercicio de las libertades y derechos individuales y civiles; pero, además, el espacio en que tiene lugar la lucha por imponer la hegemonía política y cultural. El resultado final fue que prevaleció la posición asociacionista como consecuencia de la Revolución Industrial. Sin embargo, el liberalismo siguió, a un tiempo, dos estrategias: la que concebía a la sociedad civil como el espacio natural del libre desarrollo del individuo, en contraposición al gobierno, y la que concebía al Estado como depositario de la voluntad general y garante político de las libertades individuales. El común denominador que tuvieron todas las expresiones liberales -concluye Matteucci (1983)- fue la defensa del Estado liberal: que garantiza los derechos del individuo

\footnotetext{
${ }_{9}$ Por las nuevas condiciones históricas de su resurgimiento se le ha denominado neo-liberalismo.
} 
frente al poder político, mediante formas de regulación y fundamentalmente de representación política.

En todo caso, lo que interesa destacar es que la sociedad civil se constituyó en el espacio del ejercicio del liberalismo en cualesquiera de sus manifestaciones (asociacionista, individualista, corporativista, ético, utilitarista, y otras) y en el reino del ejercicio individual o de cualquier otra forma colectiva que asuma la iniciativa privada, la libertad de empresa y la libre competencia. Así, la burguesía liberal democrática buscará permanentemente ejercer su hegemonía y legitimar su programa político y económico liberal en la sociedad civil. Empero, la dialéctica Estado/sociedad civil quedará históricamente sujeta a la lucha por el control del aparato de Estado (sociedad política), que tanto las clases dirigentes como las clases subalternas buscarán controlar, para imponer la hegemonía de su programa político (independientemente de su orientación ideológica), ya sea con predominio de la sociedad política (modelo autoritariodictatorial), o bien, de la sociedad civil, legitimando sus prácticas a través de la hegemonía política y cultural sobre la población (modelo consensual-democrático). A esta lógica de la configuración de cualquier sistema hegemónico quedará supeditada la educación.

Desde el origen mismo del liberalismo como ideología política y económica, se justificaba la libre competencia entre las instituciones educativas públicas y privadas y la privatización de la enseñanza, tomando como punto de referencia la racionalidad del funcionamiento del mercado. En esta tesitura, la fundamentación ideológica del liberalismo educativo, que tiene como núcleo ideológico fundamental la visión mercantilizada de la educación, surge como una respuesta a las necesidades históricas concretas de la burguesía ascendente de configurar un sistema hegemónico, tanto desde el punto de vista político como cultural. Un claro ejemplo fue el planteamiento educativo de Condorcet $^{10}$, quien en nombre de la libertad, rechaza el monopolio estatal en educación. En este pasaje de Ponce (1987) se pone de relieve el origen de esas tendencias que se manifestarán como constantes históricas en la evolución de la política educativa ${ }^{11}$ :

Las escuelas privadas deben vivir al lado de las escuelas del Estado, porque las estimularán con su rivalidad. Libre competencia entre las escuelas del Estado y las escuelas particulares, y ninguna intervención política del Estado en las escuelas: eso es en lo esencial lo que quiere

\footnotetext{
${ }^{10}$ Sin embargo, Condorcet preconizó la gratuidad de la enseñanza, aunque con un carácter selectivo y no generalizado a todos los sectores sociales.

${ }^{11}$ Este principio ideológico se manifestará como una constante hasta la actual sociedad neoliberal.
} 
Condorcet. (...) En resumen, pues, Condorcet desea que el Estado inaugure escuelas y pague maestros, pero no que ejerza sobre estos la más mínima tutela (Ponce, 1987, p. 141).

No obstante, una vez proclamada la República, Condorcet dio un giro ideológico: “(...) tan pronto la burguesía tomó en sus manos la máquina del Estado, Condorcet afirmó de inmediato que la vigilancia y la dirección del Estado eran en ellas necesarias" (Ponce, 1987, p. 142). Es ésta una ostensible manifestación del papel de racionalización ideológica que asumen los intelectuales acomodándose a los intereses de la clase dirigente: las posiciones de los intelectuales orgánicos fluctúan de acuerdo con la estrategia que impone la coyuntura política para asegurar la hegemonía del grupo social dominante. Claro está, en el contexto sociohistórico del triunfo de la Revolución Francesa con el ascenso de la burguesía al control del Estado -en el que Condorcet desempeña su papel de intelectual como integrante de la intelligentsia-era preciso que el Estado asumiera una función educativa que contribuyera en-la articulación de un sistema hegemónico, y que al mismo tiempo, le confiriera unidad al nuevo bloque histórico: el orden sociopolítico, económico y cultural de la burguesía triunfante. Hito histórico en que el Estado francés asume a plenitud la función político-ideológica de la educación.

\section{Estado-nación, nacionalidad y ciudadanía}

El surgimiento del Estado-nación representó el triunfo político de los ideales de la Revolución Francesa. El núcleo de las aspiraciones políticas de oposición al absolutismo monárquico y a las expresiones políticas del antiguo régimen, estaba constituido por tres elementos básicos: un Estado centralizado, un concepto de soberanía como sustento del mismo y una burocracia centralizada (Wagner, 1997). Desde el punto de vista político, se podría afirmar que representó el punto de inflexión en el ascenso de la burguesía a la escena política europea en los siglos XVIII y XIX. Es, por consiguiente, un producto histórico del desarrollo del sistema capitalista, de su sistema político, del avance cultural de las variadas formas sociales modernas (Giddens, 1999) y la columna vertebral de nuestro mundo contemporáneo (Amín, 1999). En la base de su instauración, está el universalismo de la razón ilustrada, como necesidad de libertad individual regulada, que asume una dimensión de poder político: razón de Estado o "estatalización de la razón" (Bobbio, 1976). Esa regulación de la libertad se concretó en una forma de Estado, que comprende dos procesos:

Primero, el poder se centraliza, abarcando el ámbito de las relaciones políticas y adjudicándose el monopolio de la violencia legítima, la soberanía en 
su territorio y el ejercicio de la soberanía (Cortina, 1999). Aquí, se delimita la esfera de la sociedad política (en la designación gramsciana) o Estado. La política en el marco del nuevo ordenamiento, como lo ha expresado Gramsci (1975, p. 107), se transformó en sinónimo de política parlamentaria: "Existe la convicción-observa a este respecto-de que con las constituciones y los parlamentos se inició una época de 'evolución natural' y que la sociedad encontró sus fundamentos definitivos porque eran racionales".

Segundo, el Estado se despersonaliza, en aras de una racionalidad formalizada jurídicamente. Surge así, el llamado gobiemo de las leyes: "La esfera política se separa de la esfera económica y se convierte -afirma Barcellona (1996, p. 47)- en un ámbito autónomo y limitado que tiene frente a sí a la sociedad civil y a los derechos de los ciudadanos". Estamos en presencia del momento histórico de la separación de las esferas de lo público y lo privado. Esta separación da lugar al espacio sociopolítico en que se efectúa el proceso hegemónico de las clases dirigentes y el entramado de las interrelaciones de los distintos actores: la sociedad civil. De esta manera, el Estado en su dimensión de ordenamiento político deviene en ordenamiento jurídico, y la protección de los derechos naturales da lugar, en la tradición liberal, a un proceso de regulación político-jurídico que desembocó en el Estado de derecho. Claus Offe se refiere a este hecho histórico así:

Todo lo que los primeros filósofos liberales tenían que hacer era argumentar que la realización de un conjunto de normas alternativo produciría una felicidad mayor en la comunidad. Lo hicieron atacando el orden institucionalizado y explícitamente normativo de la vieja sociedad y comparándolo con la nueva ecuación liberal-una ecuación que, por supuesto, triunfó sólo porque se convirtió en el programa y la ideología de la emergente clase de mercaderes e industriales capitalistas-(Offe, 1992, p. 48).

La nacionalidad y la ciudadanía surgen a raíz de la consolidación del Estado-nación y en el nuevo espacio que se abre al despersonalizarse el poder con el gobiemo de las leyes. El principio de la nacionalidad fue, entre otros, uno de los lazos de legitimación del Estado, y no fue si no hasta la Revolución Francesa cuando se convirtió en uno de sus pilares. Es así como la idea de Estado-nación se convierte en la forma política hegemónica de la modernidad. Matteucci (1982, p. 910) afirma que: "El Estado nacional, capaz de dar una expresión política al espíritu de la nación, sigue siendo la expresión sintética de la era liberal". Por ello, la ideología del Estado-nación, como lo indica 
Llobera (1995), es hegemónica en el periodo moderno, independientemente de las nacionalidades que estén detrás de cada Estado. Al referirse a este proceso sociohistórico, Adela Cortina (1999, p. 56) señala que el concepto de ciudadanía surge con la aparición del Estado moderno "ligado en principio a los dos lados de la expresión 'estado nacional', 'Estado'y 'nación'. Al imponerse el imperio de la ley en el Estado, los ciudadanos adquirirán la nacionalidad de su país; la nacionalidad será así, el estatuto legal (reconocido por el derecho internacional) por el que los individuos pertenecen a un Estado.

A esta noción de ciudadanía, se liga el principio educativo fundamental del ethos revolucionario en Francia, que defendían los enciclopedistas: el destino práctico, concreto, pero a la vez, técnico, cívico y humano de los programas de enseñanza ${ }^{12}$. Por lo tanto, como principio la educación debía poseer un espíritu renovador y en su función social, adaptada en un modelo de organización social basado en la soberanía nacional y la libertad política (en la noción liberal del término), concebida en un sentido cívico que propiciara la integración de la niñez en el cuerpo social y que formase el nuevo ciudadano de una democracia libre (Hubert, 1952). Esta visión ideológico-política es una diáfana manifestación de la racionalidad modernista que adquirió la educación en el proceso de conformación del Estado-nación (en su forma política republicana) y la noción de ciudadanía.

Un claro ejemplo del papel de la educación ligado a la emergencia de la noción de ciudadanía, del concepto de lo público y a la configuración del pensamiento democrático burgués, se encuentra en el pensamiento político de Montesquieu. El papel de la ciudadanía en la concepción de la república democrática y particularmente del mantenimiento del principio de la democracia expuesta en su obra El espíritu de las leyes (1690), está vinculado -según Chevalier (1981) - a la virtud (en un sentido político) entendida como la exigencia del individuo de sacrificarse a sí mismo (de su egoísmo, de su indisciplina, de su avidez, de todos sus apetitos) por el Estado y el interés público. Una virtud que sobreviene en un recurso sin el cual no es posible que funcione la democracia. En consecuencia, para que esa virtud no cese nunca el gobierno democrático tiene "la necesidad de la omnipotencia de la educación para imprimir en los niños ese renunciamiento de símismo, cosa siempre muy penosa, ese amor

\footnotetext{
12 En la obra: Historia de la pedagogía (la cual no obstante su antigüedad consideramos de un gran valor) Renè Hubert (1952) señala respecto de los programas de estudio del proyecto revolucionario que: "Condorcet quiere que se enseñe, 'no sólo lo que es útil saber como hombre, como ciudadano, en cualquier profesión a que se lo destine, sino también todo lo que puede serlo para cada gran división de esas profesiones'. Prevé para las escuelas secundarias (que corresponden en su proyecto a nuestras escuelas primarias superiores) una enseñanza principalmente científica, en la cual las matemáticas, la historia natural y la química, la moral y las ciencias sociales, y aún lecciones elementales de comercio, ocupan el mayor lugar."
} 
a las leyes y a la patria, que exige una continua preferencia del interés público sobre el propio" (Chevalier, 1981, p. 113). El espíritu de la Revolución establece, como uno de sus principios fundamentales, que la enseñanza es ante todo asunto del Estado: adquiere un rango de una función y una obligación públicas. En Francia, la Constituyente ya había proclamado desde el voto de la Constitución de 1791: "Se creará y organizará una instrucción pública común a todos los ciudadanos, gratuita respecto a las partes de enseñanza indispensables para todos los hombres, y cuyos establecimientos serán distribuidos gradualmente, en una relación combinada con la división del reino".

Es interesante hacer notar, a tenor de lo que venimos exponiendo, que la justificación de Rousseau de la vuelta hacia la educación natural, a partir de su visión inmanentista, surge del reconocimiento de la inexistencia en su tiempo de la educación pública, la cual no puede existir porque "donde no hay patria no hay ciudadanos. Quédanos pues la educación doméstica, o de la Naturale$z a$ ". Su Emilio (1762) es una obra de reflexiones sobre la educación y "una propuesta educativa para una sociedad en la que no existía una educación pública adecuada". Es clara la vinculación que realiza Rousseau de la educación pública a la condición de ciudadanía. También hace una referencia a la educación nacional en Consideraciones sobre el gobierno de Polonia, siempre en el contexto del inmanentismo, abogando por una educación que surja como un proceso natural a partir de las necesidades del niño (Fernández, 1985). Las preocupaciones educativas de Rousseau son, ciertamente, una manifestación de un contexto histórico de cambio en que las figuras de nación, patria, ciudadanía y la configuración de las funciones del Estado-nación mostraban un claro proceso genesíaco.

Respecto de la interrelación sociohistórica de la nación y la modemización, Touraine (1993, p. 178) explica que la nación no es la figura política de la modemidad, sino el actor principal de la modemización, de donde concluye que "es el actor no moderno el que crea una modernidad cuyo control tratará de conservar al mismo tiempo que aceptará perderlo en parte en provecho de una producción y de un consumo internacionalizados". Este punto de vista reviste particular importancia, porque apunta en forma precisa, según Touraine, a la identificación de su nacionalismo con la visión universalista de la razón. Esto explica el principio básico del espíritu revolucionario que defendió Condorcet en Francia: el carácter eminentemente nacional de la educación, que a su vez debía ser profundamente humana. Su interés radicaba en sustraer la instrucción pública de la autoridad de la monarquía o de sus consejos, para someterla, exclusivamente, a la Asamblea como personificación de la Nación y de sus representantes, que expresaban la voluntad general concebida como la razón 
pública. Esta posición de naturaleza ideológico-cultural, estará, al mismo tiempo, en la base de la racionalización de la colonización europea, en la cual la educación representará un papel fundamental para la imposición de la visión hegemónica del mundo occidentalista preconizada por las burguesías de las sociedades capitalistas centrales. De igual forma, hay que tomar en consideración que conforme el desarrollo de las fuerzas productivas elevó a sus máximas expresiones el desarrollo capitalista industrial, la identificación entre el nacionalismo y la modernización se profundizó. Pero será el juicio histórico retrospectivo el que pondrá en evidencia el triunfo o fracaso de una sociedad racionalizada. Empero, es posible concluir que con ciertas modificaciones, producto de la mutación de las condiciones sociohistóricas, este sustrato ideológico se ha mantenido durante toda la fase de construcción de la modernidad hasta nuestros días.

\section{Universalidad y etnocentrismo}

Según Barcellona (1996, p. 65), el Estado nacional construye el sujeto nacional a imagen y semejanza del sujeto individual, sin posibilitar las modalidades de integración de las masas, por lo que el universalismo racionalista se convierte "rápidamente en el nacionalismo del 'espíritu del pueblo' y de la 'misión histórica' de la exportación del proceso de civilización y modemización". Esta unidad de visión social y de sentido histórico de la modernización, se fundamenta en la racionalidad liberal burguesa, cuyo afán colonialista expansivo perseguía a un tiempo la imposición de dominación estructural y de imposición hegemónica. Es oportuno recordar, a propósito de esta consideración, que en el marco histórico social de la Revolución Industrial y la sociedad capitalista y burguesa de la Inglaterra del siglo XIX, aparecieron teorías y doctrinas que dieron origen a las corrientes de pensamiento social contemporáneas; estas influyeron en el desarrollo disciplinario de las ciencias sociales apoyadas en principios epistemológicos y axiológicos que justificaban la desigualdad y diferenciación social. La aparición del Origen de las especies, publicada por Darwin (1859), revolucionó el conocimiento biológico y devino en el paradigma científico en el cual se fundamentó el pensamiento darwinista en su versión social, preconizado por Herbert Spencer en el siglo XIX. Cassirer sentenció al respecto que: "El concepto de 'evolución' fue presentado como la clave llamada a resolver todos los misterios anteriores de la naturaleza y todos lo 'enigmas del universo"” (Citado por Moya, 1975, p. 39). La "analogía orgánica" que Spencer estableció entre el organismo biológico y el "organismo social" (como "biología social": catecismo seudocientífico que entroniza el dogma 
absoluto de la evolución y el paradigma organicista de la vida social). Asimismo, sirvió de argumento epistemológico y axiológico justificativo del nuevo orden social surgido después del antiguo régimen y con la Revolución Industrial.

Otro ejemplo fue el del positivismo sociológico de Comte con su teoría de las tres etapas históricas del desarrollo social: teológica, metafísica y positiva, que pretendió establecer un reduccionismo epistemológico a partir de la física, creando una ciencia de la sociedad como física social correspondiente a la última etapa positiva: la sociedad capitalista de su tiempo. Como lo indicó Gramsci (1975, p. 107), el éxito de la sociología que tuvo lugar en la segunda mitad del siglo XIX a raíz de la aceptación generalizada de las doctrinas evolucionistas y positivistas, contribuyeron a conferirle racionalidad al concepto de política que estaba estrechamente vinculado a la evolución histórica de la sociedad racional, por lo que su estudio podía ser realizado por el método de las ciencias naturales. Pero, igualmente, habría que añadir que sirvió de racionalización ideológica de las condiciones infrahumanas a que estuvieron sometidos grandes contingentes de la clase trabajadora (incluso población infantil), en el curso de la industrialización y la consolidación de la sociedad capitalista burguesa. Gran paradoja histórica: el darvinismo biológico devino en darvinismo social. Este último se convertirá en una constante ideológica, que marcará las formas hegemónicas de dominación de las clases dominantes liberales en el plano nacional y en los procesos de expansión colonial e imperial, en el siglo XIX y a lo largo del siglo XX.

Carnoy (1985, p. 35) pone de relieve que en el periodo mercantil del imperialismo europeo, la educación escolar formal tuvo un carácter exclusivista: en la metrópoli sólo los hijos de los ricos podían acceder al sistema escolar. Las oportunidades educativas sólo estaban garantizadas para la aristocracia y la clase mercantil, privando el interés de que primordialmente sus hijos llegaran a ser profesionales y burócratas. Para los sectores populares, cuando podían ingresar, sólo existía una instrucción religiosa. En las zonas periféricas, como el caso de América Latina, la escuela formal desempeñó el triste papel de instrumento colonizador de los indígenas para utilizarlos como fuerza de trabajo en las plantaciones, minas o haciendas de los portugueses y españoles. $\mathrm{O}$, como el caso de la India, en que la Compañía de las Indias Orientales Británicas creaba universidades musulmanas para lograr el apoyo de la minoría selecta musulmana, y así formar una élite adherida a la cultura europea y sus valores universales, con la intención de establecer la hegemonía política y cultural de la sujeción colonial.

Esta visión entrañó, desde el punto de vista de su fundamento racional, una dimensión ideológica de naturaleza sociopolítica y cultural en la que se 
apoyará la expansión mundial del pensamiento liberal burgués en las esferas social, económica y política. La teoría evolucionista, explica Picó (1999, p. 122), se constituirá en paradigma científico y origina, en paralelo, una ideología que racionaliza y legitima "la superioridad de la civilización europea sobre cualquier otra forma o manifestación cultural de los pueblos primitivos”, y la supremacía de la raza blanca sobre las otras del mundo periférico, a las que se considera en estadios evolutivos inferiores; con lo cual emerge la visión ideológica culturalista del etnocentrismo cultural europeo, que se manifestará en el curso de la modemidad.

La noción de civilización quedará de esta manera supeditada, en su sentido connotativo, a la cultura europea que universalizará su proyecto hegemónico cultural de modelo civilizatorio al resto del mundo. La ética y moral burguesa encontrará en la teoría darviniana sobre "la supervivencia de los más aptos y la selección de los mejores”, una sólida justificación y racionalización sobre las condiciones sociales de injusticia que caracterizarán la industrialización y las manifestaciones más significativas de la modemización capitalista y su adaptación a la lógica de la acumulación de capital en el plano mundial.

\section{Razón, progreso y modernización}

La noción de progreso es una de las manifestaciones culturales y civilizatorias más representativas del Siglo XVIII, al punto de representar la ruptura con la idea de la providencia divina como omnipresente del destino humano y de la historia, por una noción providencial que coloca la razón científica como el eje alrededor del cual gira toda acción humana y social, y el principal vector histórico de toda la humanidad. Giddens se refiere a este cambio sociocultural en estos términos:

La divina providencia ha sido por mucho tiempo la idea orientadora del pensamiento cristiano, sin esas orientaciones precedentes, en primer lugar, difícilmente hubiera sido posible la Ilustración. No es sorprendente que la defensa de la razón liberada de ataduras sólo remodelara las ideas lo providencial en lugar de sustituirlas. Un tipo de certeza (la ley divina) se reemplazó por otro (la certeza en nuestros sentidos, la certeza de la observación empírica), la divina providencia se reemplazó por progreso providencial. Más aún, la idea providencial de la razón, coincidió con el auge del dominio europeo sobre el resto del mundo (Giddens, 1999, p. 54). 
El hecho de que los avances de la ciencia y la técnica ocupen uno de los lugares principales, hace que el progreso se asocie con tal idea y que la visión del avance en todas las formas de la vida social esté condicionado a esa concepción; en virtud de ello, la filosofía de la historia tuvo como núcleo fundamental la noción de progreso. La noción de progreso queda subordinada a una suerte de sincretismo del racionalismo cartesiano, el experimentalismo de Bacon, de Locke y de Newton, de una expresión universal y abstracta que emana del sistema lógico que el hombre descubre (resultado de un análisis y generación de ideas) de la Naturaleza. Y a la vez, con filósofos como Condillac, D' Alambert y Turgot que animan la tendencia modernista educativa que asume el método del análisis y la generación de las ideas escrutando la Naturaleza, la historia y al ser humano.

A esta visión hay que complementar otro argumento fundamental que explica, desde una perspectiva social y política, la lógica racional a la que se adscribe la educación, y que tiene que ver también con la noción de progreso. Alain Touraine (1993, pp. 89-91) observa que la idea de progreso ha "querido imponer la identidad del crecimiento económico y del desarrollo nacional", afirma además, que "el progreso es la formación de una nación como forma concreta de la modernidad económica y social". Esta interpretación parte de la consideración de que en la filosofía de las Luces, la modernidad se hallaba separada de la modernización, porque el progreso era todavía una idea. Pero el progreso se manifestará como un proceso histórico de cambio estructural alterando la vida de la mayoría con la emergencia de las formas de producción y de trabajo y su impacto en la industrialización, la urbanización y la extensión de la administración pública. También plantea que la idea de desarrollo da primacía a la política y la de racionalización al conocimiento; la idea de progreso ocupa, así, un lugar intermedio, central, entre ambas. Con esto la idea de progreso influirá en dos procesos: por un lado, la afirmación de la identidad entre políticas de desarrollo y triunfo de la razón; y por el otro, la aplicación práctica de la ciencia a la política, vinculando una voluntad política a una necesidad histórica.

Sin embargo, desde sus orígenes en la filosofía de la historia de la burguesía emergente, el concepto de progreso entraña una antinomia. De una parte, se le atribuyeron aspectos de emancipación social, así el progreso fue liberalización de las limitaciones tradicionales de autodesarrollo del hombre. De otra, el progreso se refirió a la dimensión técnica de la modemización de instrumentos e instituciones socialmente productivas (vinculadas al proceso de acumulación capitalista); el progreso fue liberalización entendida como autonomía y separación de la eticidad tradicional (Dubiel, 1993). Esta antinomia se constituirá 
en una constante en el proceso histórico de configuración de la modernidad, y conforme se realiza el avance del proceso de modernización, la burguesía abrazará con más fervor la segunda visión a favor de sus intereses hegemónicos. La idea asociada al progreso desde un enfoque economicista y de marcado acento utilitarista en lo social, definirá la tónica a partir de la cual se realizará la génesis del proceso de modernización, concebido como crecimiento económico y desarrollo nacional. Desde un punto de vista sociohistórico, la dialéctica de la relación entre el proceso de avance del capitalismo y la permanente exigencia de reconstruir y legitimar permanentemente el proyecto hegemónico de la burguesía, en los ámbitos nacional e internacional (a través de sus alianzas), se ha manifestado en la mutación histórica de la concepción de progreso. Por esto, no resulta sorprendente que esa relación haya sido el principal factor de definición y redefinición de las funciones de la educación, con arreglo a las exigencias impuestas por el proceso de modernización, desde su inicio hasta el día de hoy.

Las modalidades tradicionales del orden social -como sostiene Giddens (1999)- fueron superadas por la modernidad, tanto en su extensión como en su intensidad, al punto que la modernidad produjo cambios característicos más profundos que todos los anteriores. El progreso, en efecto, no será sólo una idea, como en la época de la Ilustración, sino que se manifiesta en las formas de producción y trabajo, en un marco de profundas transformaciones provocadas por los cambios estructurales en las esferas productivas, la ampliación de la administración pública y el proceso de urbanización que modifican aceleradamente las condiciones de la vida social (Wagner, 1997; Touraine, 1993). El discurso de la modernidad, apoyado en la idea de libertad y autonomía, posibilitó reinterpretar, con un nuevo sentido histórico, las nuevas práctica sociales. La educación ha participado en la nueva concepción del progreso e integrando, con otras no menos importantes, el corpus teórico del pensamiento historicista moderno y liberal, y articulada al proceso sociohistórico de la modemización capitalista.

\section{Modernización y racionalidad técnica}

La elevación de la razón al rango de entidad rectora y organizadora de la vida social ha sido, como lo hemos analizado, uno de los rasgos distintivos más importantes de la modernidad. La filosofía de la historia ciertamente descansa en la noción de progreso. Al punto que devino en un elemento vertebrador de la ideología modernista. A la altura del siglo XVIII, el avance de las ciencias y de las técnicas respalda esta concepción. La Ilustración sostenía la idea de que el progreso debía estar presente en todas las formas de la vida social. Esto se puso 
de manifiesto en la tendencia que tenía como norte el establecimiento de formas de organización social racionales, y que al mismo tiempo, produjeron una base de racionalidad en los procesos de conformación de la vida cultural de la sociedad acordes con "el espíritu de la burguesía en ese instante: científica, escéptica y práctica, y por lo tanto deseosa de que las técnicas se despojaran de los secretos con que hasta entonces las habian envuelto las 'corporaciones'" (Ponce, 1987, p. 141). La concepción clásica de la modernidad que dominó Europa y el mundo occidental, observa Touraine (1993), tuvo como tema central la identificación del actor social con sus obras y su producción. Esta aspiración vital descansó, según él, en el triunfo de la razón científico y técnica y mediante la respuesta de la sociedad racional a sus necesidades y deseos. Así, el desenvolvimiento histórico como expresión del modernismo se vincula con el "continuo progreso de las ciencias y las técnicas, la división racional del trabajo industrial, que introduce en la vida social una dimensión de cambio permanente, de destrucción de las costumbres y la cultura tradicional (Baudrillard, citado por Giroux, 1997, p. 61). Esta concepción explica por qué la idea triunfalista de la razón y su base instrumental quedó asociada, desde el historicismo, a una visión futurista del progreso.

A las consideraciones precedentes hay que adicionar un aspecto que pone de relieve las condiciones de maduración de la racionalidad moderna capitalista en el proceso de configuración del sector público y que incidió en la estructuración del sistema educativo moderno. Habermas (1999) explica que el Estado definió la organización del sistema educativo mediante la calificación, en aras de promover la productividad del trabajo. Con el incremento de las fuerzas productivas, técnicas y humanas, en el contexto del capitalismo liberal, el Estado coadyuvó en el incremento de la plusvalía relativa favoreciendo al sector privado de la economía. Sobre esta cuestión, (1999, p. 103), puntualiza que:

Sólo con la organización estatal del progreso técnico-científico, y con una expansión sistemática de la enseñanza especializada, la generación de informaciones, tecnologías, organizaciones y calificaciones que aumenta la productividad se convierte en un ingrediente del proceso productivo en cuanto tal.

Este cambio representa una dimensión sociohistórica de la racionalidad económica en el capitalismo liberal. La vinculación por parte del Estado de la organización del sistema educativo con el progreso técnico, con lo cual se conformó un ejército laboral con distintas escalas de cualificación, influyó decididamente en la composición orgánica y técnica del capital y, por ende, en el 
desarrollo de las fuerzas productivas, la producción capitalista y el proceso de acumulación de capital.

La maduración de las condiciones estructurales sobre las que se erigió la sociedad capitalista permite, desde mediados del siglo XIX, el análisis de los fundamentos del proceso de su construcción racional lo que explica la emergencia de grandes interpretaciones desde las denominadas ciencias del espíritu que dan cuenta de la génesis de la sociedad capitalista. Una de las más representativas fue la de Max Weber a principios del siglo XX (que da origen a la sociología comprensiva) apoyada en un conocimiento empírico y objetivo. Esta visión teórica se basa, desde un punto de vista metodológico, en la aplicación de los tipos ideales: modelos o construcciones conceptuales que se formulan con arreglo a criterios de comportamiento social de máxima racionalidad). El gran aporte de Weber se basa en la tesis de que si bien los cambios económicos inciden en conformación de las sociedades, estos no son suficientes: es preciso analizar la influencia de las creencias religiosas en su estructuración económica. En La ética protestante y el espíritu del capitalismo (1904-5), explica cómo los valores ético-protestantes, se tradujeron en valores que rigen o determinan las prácticas sociales y económicas en la génesis de la formación social capitalista. En síntesis, Weber realizó un examen de la vinculación e influencia de los valores ético-religiosos como fundamentos de la racionalidad económica y social de su configuración. Según su planteamiento, esos valores devienen en una ética económica capitalista y en la razón científica instrumental adherida a la lógica medio-fines.

El diagnóstico y la visión weberiana acerca de la racionalidad modemista permiten percibir el carácter, la valoración y la dimensión que adquirió la razón instrumental y su marco axiológico en la cultura capitalista, que ha gravitado en las tesis doctrinales y políticas de la defensa la sociedad capitalista modema. Sus agudas observaciones sobre el papel de las ideas en la vida social y sus notables aportes en la comprensión de los fenómenos de poder que magistralmente desarrolló, representan uno de los más sólidos edificios teóricos en la historia del pensamiento social. Sin embargo, sus críticos, por ejemplo Sharp (1988), señalan que Weber no formuló una teoría coherente sobre la ideología, ni una visión analítico-estructural acerca de la dinámica del desarrollo capitalista en el marco de la acumulación del capital a escala mundial, ni del papel del Estado en la configuración y mantenimiento de la hegemonía política

Por otra parte, la racionalidad modernista originó teorías sociales en el avance disciplinario de la sociología y en otras ciencias sociales (como el estructural-funcionalismo) que parten de un núcleo epistemológico que presupone la funcionalidad y necesidad de la estratificación de las sociedades, en particular 
de las sociedades industriales complejas. Esta idea de la "inevitabilidad de la división social del trabajo”, de acuerdo con Sharp (1988, p. 11), se vincula con la diferenciación del poder, en las remuneraciones económicas y en la posición social que por ser "naturales", no son cuestionadas. De ahí se sigue, desde la óptica de la movilidad social, que la educación haya sido concebida como un medio de selección social para asegurar la institucionalización de la desigualdad social y de oportunidades de la sociedad de los méritos. En el trasfondo ideológico político y cultural de este enfoque, subyace una visión del cambio social que sostiene que las transformaciones científicas y tecnológicas producen más diferenciación en la división del trabajo, y en consecuencia, en los sistemas de estratificación social. Siendo así, los sistemas educativos se consideran como instituciones que se deben adaptar a los imperativos científicotecnológicos, sociales y económicos. El estructural funcionalismo, como una de las teorías del equilibrio, abordará el análisis de este asunto desde el reconocimiento de que "todas las instituciones sufren cierto grado de inercia estructural, hay retrasos culturales o desequilibrios estructurales pero gradualmente actúa la tendencia interna hacia un restablecimiento del equilibrio" (Sharp, 1988, p. 12).

La concepción del desarrollo histórico a partir de la idea de la irreductibilidad e infalibilidad del conocimiento científico y su aplicación técnica -condición de posibilidad del progreso material-social-adquirirá el rango de una de las principales tesis de la ideología modernista. Este constructo ideológico, que integra el avance tecnológico al progreso económico y social, irá adquiriendo fuerza en el curso de avance del proceso de modernización capitalista, hasta alcanzar su máxima expresión en lo que se ha dado en llamar de diversas maneras: sociedad del conocimiento, sociedad de la información, del saber, tecnológica... En virtud de esta tesis, se comprende por qué en el mundo capitalista avanzado a la racionalidad instrumental y su base material la tecnología, se les ha conferido un valor inmanente y han llegado a constituir un pilar fundamental de su sistema cultural, que no requiere de grandes relatos discursivos para asegurar su validez histórica y axiológica: la racionalidad instrumental y la tecnología se han recubierto de un halo de neutralidad moral, están "más allá del bien y del mal".

La legitimación histórica de esta tendencia alcanzará perfiles más claros con la introducción de la técnica, la tecnología y la racionalidad instrumental al mundo productivo y del mercado de las sociedades capitalistas avanzadas. La sociedad capitalista moderna reforzará esa idea y la elevará al rango de mito prometeico el progreso de la humanidad, que quedará subordinado y supeditado en gran medida a la razón instrumental y al desarrollo tecnológico. Así, el 
conocimiento devino en poder, y la tecnología en su instrumentación práctica. La modernización capitalista apoyada en la racionalidad tecnológica y la introducción de las aplicaciones tecnológicas a la esfera de la producción y la comunicación, le conferirá al avance tecnológico una decidida vinculación orgánica entre las esferas del sistema económico y la hegemonía política y cultural.

\section{LA RACIONALIDAD EDUCATIVA MODERNISTA: DESIGUAL- DAD Y MERITOCRACIA}

Lo tratado anteriormente, nos ha permitido acercarnos un poco más a la comprensión de la configuración del papel de la educación que tuvo lugar en la génesis sociohistórica de la modernidad. Por último, nos referiremos a la forma en que se manifiesta la racionalidad educativa en la cultura hegemónica de la sociedad capitalista.

La fuerza de la educación en el contex to de la sociedad racional, según el planteamiento de Eagleton (1997), se orientó fundamentalmente a regular la conciencia sometida al escrutinio científico y orientada al logro de la felicidad humana. Por ello, es preciso dimensionar la reorientación del papel social y político de la educación en el marco de la modemidad, como uno de los giros fundamentales de desprendimiento del dogmatismo y de toda forma irracional de entender y actuar en el mundo social; a la vez, desde una perspectiva hegemónica ese cambio representa una asimilación ideológica de la cultura burguesa a la cual se le atribuye, según el análisis precedente, una dimensión universalista. Como lo expresa Touraine:

El enseñante no es un educador que intervenga en la vida privada de los niños, que no deben ser más que alumnos; es un mediador entre ellos y los valores universales de la verdad, del bien, y de lo bello. La escuela también debe reemplazar a los privilegiados herederos de un pasado rechazado, por una élite reclutada mediante las pruebas impersonales de los concursos (Touraine, 1999, p. 27).

Recurramos para comprender esta cuestión a J. J. Rousseau, uno de los máximos exponentes del pensamiento racional modernista en el campo pedagógico. Entre los rasgos característicos de su obra sobresalen tanto su separación del concepto de civilización imperante en su tiempo, como la visión optimista de la cultura de los enciclopedistas (recuérdese su ruptura con los enciclopedistas). Su obra se basa en el principio de búsqueda de la transparencia y la lucha contra los obstáculos que impiden el conocimiento y la comunicación, en una sociedad "transparente como el pensamiento científico", opuesta 
a la arbitrariedad, la dependencia y el espíritu reaccionario; en esta orientación se apoya su obra como naturalista, sus invenciones como musicólogo, su crítica de la sociedad y su programa educativo (Touraine 1993, p. 27). Dubiel (1993) afirma que la tradición clásica de la concepción de sociedad de Rousseau corresponde a la democracia, entendida no sólo como una forma de Estado institucional, sino también como una forma de vida cultural. Así pues, el ideal educativo de Rousseau persigue un modelo de sociedad concordante con el espíritu de las Luces ${ }^{13}$; no en vano se le considera que dentro de los filósofos ilustrados fue él quien aplicó el concepto de cultura de manera más amplia relacionándolo con la educación de la persona humana (Picó, 1999). Ciertamente, hay que reconocer que su gran contribución fue demostrar que la educación como sistema doctrinal requiere de una fundamentación filosófica general del hombre y de la sociedad.

Según Rousseau, la base de la desigualdad social tiene su fundamento en la desigualdad natural. Este principio se ha constituido en un elemento cardinal en que las tradiciones de pensamiento conservador han fundamentado su tesis de la meritocracia. Respecto de la tesis de Rousseau relativa a la desigualdad, Dubiel (1993) explica que la desigualdad teóricamente vista como heterogeneidad en los hombres, no presenta problema, porque apunta a las características de: sexo, constitución física, procedencia étnica y regional. Sin embargo, observa que la desigualdad social, según la distinción de Rousseau, partió de una valoración basada en la distribución desigual de bienes económicos, de medios de poder políticos y expectativas culturales. Esos dos principios han llevado a los ideólogos políticos conservadores a inclinarse a atribuir el problema de los intereses individuales, capacidades y motivaciones de rendimiento como inherentes a las causas naturales. Con estos fundamentos, la teoría de la meritocracia sostiene que el orden social debe construirse a partir de la heterogeneidad natural y de la valoración de la desigualdad social. Es claro que esta forma de pensamiento encuentra en el principio aludido de Rousseau, un sólido fundamento epistemológico y axiológico.

El naturalismo de Rousseau asume una valoración que subordina lo humano a lo natural y que se proyecta desde una dimensión totalizadora a la vida social. En esta tesis, se encuentra en estado embrionario, como lo hace notar Gil Villa (1994), el fundamento que justificará (como racionalización ideológica) la posición elitista de la acción que plantea la existencia de dos circuitos de escolarización: el masivo y el especial. El primero, concebido más como

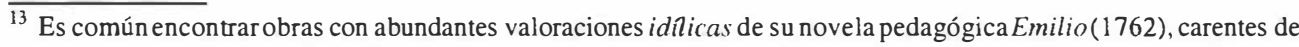
todo rigor interpretativo crítico. Mucho menos que realicen una aproximación hermenéutica-crítica de su contenido y del pensamiento pedagógico en el conjunto de toda su obra, desentrañando su trasfondo ideológico sociopolítico.
} 
instrucción (desde un enfoque curricular predominantemente cognitivo) que educación en su sentido integral; y el segundo, con un carácter selectivo, exclusivista y aristocrático. A este respecto, menciona que:

(...) la importancia de las teorías de Rousseau y del modelo educativo que representan reside en su papel del modelo a imitar por el circuito masivo de escolarización. Podría decirse que el sistema educativo sobrevive, es decir, no es cambiado sustancialmente desde entonces, porque promete trabajar por la reconversión del circuito masivo con arreglo a los criterios que rigen en el circuito especial. De esta forma funcionan los mecanismos que se legitiman mediante el recurso al autoperfeccionamiento: 'se ha avanzado pero no es suficiente, no obstante, estamos en ello'. Mediante estas palabras se suele justificar el tecnócrata que se nutre de cierta pedagogía supuestamente reformista (Gil Villa, 1994: 30).

Efectivamente, las tesis meritocráticas encuentran su justificación básica apoyándose al menos en tres fundamentos teórico-ideológicos: a) en la idea enciclopedista, que sostiene que los privilegios legítimos son los que concede la naturaleza; b) en el pensamiento de Rousseau relativo a las aptitudes naturales del individuo; y c) en la visión organicista de la vida social que preconizó Spencer. Varias teorías modernas han surgido basadas en esta concepción, entre ellas ha ocupado un lugar central la teoría sociológica funcionalista de la meritocracia, con su justificación de la estratificación jerarquizada de la estructura social. Esta teoría, ha brindado históricamente una decidida contribución al surgimiento de muchas propuestas de modelo social de desarrollo nacional de corte tecnocrático (sobre todo, después de la Segunda Guerra Mundial), promovidas por los Estados nacionales y organismos regionales e internacionales. En el campo educativo esta concepción, renovada con los aportes de la razón instrumental de nuevo cuño, sigue siendo utilizada como fundamento ideológico por las nuevas élites tecnocráticas para justificar sus posiciones pedagógicas neoliberales y neoconservadoras, como clara expresión del darwinismo social.

Por otra parte, la vinculación de los procesos educativos a la génesis de la sociedad racional y su adscripción a la idea de progreso, está estrechamente relacionada con el cambio histórico de la idea de Estado. Debemos tener presente, siguiendo a Norberto Bobbio (1976), que el pensamiento político moderno, desde Hobbes hasta Hegel, se considera al Estado o sociedad política respecto del estado natural o sociedad natural, como el momento supremo y definitivo. El Estado representa el momento en el cual el reino de la fuerza 
desbordada, se transforma en el reino de la libertad regulada. "El Estado se concibe como producto de la razón, o como sociedad racional, en el que sólo el hombre puede llevar una vida conforme a la razón, es decir, conforme a su naturaleza" (Bobbio, 1976, p. 19). De aquí que la racionalización del Estado, en la perspectiva iusnaturalista de Rousseau, lleve implícita una tácita aceptación de la desigualdad social (como condición natural y, por ende, social) que la sociedad racional o el Estado protege (Bobbio, 1976, p. 98). En su obra Discurso sobre el origen y los fundamentos de la desigualdad entre los hombres, Rousseau (1755) subrayaba que la desigualdad de crédito y de autoridad se toman inevitables entre los individuos cuando en su convivencia social no tienen más remedio que compararse entre sí. Entre las diferencias que destacaba como principales están la riqueza, la nobleza o el rango, el poderío y el mérito personal, distinciones principales a través de las cuales se suele medir y clasificar los individuos dentro de la sociedad. La importancia central de estas desigualdades lo lleva a concluir que el acuerdo o el conflicto de esas diferenciaciones son la base para determinar si un Estado está bien o mal constituido. Por consiguiente, la sociedad racional representa la instauración legítima de un orden social en que prevalece la injusticia y la inequidad social, a la cual la educación se somete entronizando el reino de la meritocracia. La impronta de esta concepción, en efecto, se manifestará de diversas maneras en la definición del papel de la educación, como parte del proyecto hegemónico sustentado por las clases dominantes en el curso del proceso de modernización, hasta manifestarse en toda su plenitud hoy en día, como ideología, categoría social y práctica socioeducativa en la sociedad neoliberal ${ }^{14}$.

En síntesis, la sociedad racional es el resultado del desarrollo históricoestructural de la formación social capitalista, en el cual la educación participó en la génesis histórica del proyecto hegemónico liberal, dando origen al concepto moderno de política educativa. La asunción de las funciones educativas por el Estado, como parte de la esfera de lo público y su articulación a su aparato, devino en la conformación histórica de un proceso hegemónico educativo.

\footnotetext{
${ }^{14}$ Una referencia a este aspecto se encuentra en el ensayo "Capitalismo global y cambio educativo. Los fundamentos estructurales e ideológicos de la política educativa neoliberal". Cf. Miranda (2004).
} 


\section{REFERENCIAS BIBLIOGRÁFICAS}

Amín, S. (1999). El capitalismo en la era de la globalización. Barcelona. Paidós.

Apple, M. W. (1996). El conocimiento oficial. La educación democrática en una era conservadora. Barcelona, Paidós.

Barcellona, P. (1996). Postmodernidad y comunidad. El regreso de la vinculación social. Valladolid. Editorial Trotta.

Bobbio, N. (1976). Gramsci y la concepción de la sociedad civil. Barcelona. Avance.

Carnoy, M. (1985). La educación como imperialismo cultural. México. Siglo Veintiuno.

Cerroni, U. (1986). Introducción al pensamiento político. México. Siglo Veintiuno. Chalmers, A. (2000). ¿Qué es esa cosa llamada ciencia? Madrid. Siglo Veintiuno.

Chevalier, J. J. (1981). Los grandes textos políticos. Desde Maquiavelo a nuestros días. Madrid. Aguilar.

Cortina, A. (1999). Ciudadanos del mundo. Hacia una teoría de la ciudadanía. Madrid. Siglo Veintiuno.

De Gortari, E. (1971). Principios de lógica. México. Editorial Grijalbo.

Dubiel, H. (1993). ¿Qué es neoconservadurismo? Barcelona. Editorial Anthropos.

Eagleton, T. (1997). Ideología. Una introducción. Barcelona. Paidós.

Fernández M. (1986), Introducción de la Didáctica Magna de Comenius. Madrid. Akal.

(1985). Trabajo, escuela e ideología. Madrid. Akal.

Giddens, A. (1999). Consecuencias de la modernidad. Madrid. Alianza Editorial.

Gil Villa, F. (1994). Teoría sociológica de la educación. Salamanca. Amarú Ediciones.

Giroux, H. A. (1997). Cruzando límites. Trabajadores culturales y políticas educativas. Barcelona. Paidós.

Gramsci, A. (1975). Notas sobre Maquiavelo, sobre política y sobre el Estado moderno. México. Juan Pablos Editor.

Habermas, J. (1998). "La modernidad un proyecto incompleto". En VV. AA. (1998). La postmodernidad. Ed. Hal Foster. Barcelona. Kairós.

Cátedra.

Hubert, R. (1952). Historia de la pedagogía. Buenos Aires, Kapeluz.

Khun, T. (1986). La estructura de las revoluciones científicas. México. Fondo de Cultura Económica.

Laski, O. (1974). El liberalismo. México. Fondo de Cultura Económica.

Llobera, J. R. (1995). "Estado soberano e identidad nacional en Europa actual". En VV. AA. (1995). Culturas, estados, ciudadanos. Una aproximación al multiculturalismo en Europa. Madrid. Editorial Avance.

López, F. (1977). Origen y evolución del liberalismo europeo. México. UNAM.

Manacorda, M. (1987). Historia de la educación II. Del 1500 a nuestros días. México. Siglo Veintiuno. 
Mateucci, N. (1982). "Liberalismo". En Bobbio, N. y Mateucci, N. (1982). Diccionario de política. Madrid. Siglo Veintiuno.

Miranda, G. (2004) "Capitalismo global y cambio educativo. Los fundamentos estructurales e ideológicos de la política educativa neoliberal". En Revista Educare $N^{\circ}$ VII, año 2004 (pp. 13-42), Universidad Nacional, CIDE. Costa Rica. EUNA.

Moya, C. (1975). Sociólogos y sociología. México. Siglo Veintiuno.

Offe, C. (1992). "Dos lógicas de acción colectiva”. En La gestión pública. Ministerio de Trabajo y Seguridad Social. Madrid.

Picó, J. (1999). Cultura y modernidad. Seducciones y desengaños de la cultura moderna. Madrid. Alianza Editorial.

Ponce, A. (1987). Educación y lucha de clases. Barcelona. Akal.

Portelli, H. (1977). Gramsci y el bloque histórico. México. Siglo Veintiuno.

Sabater, F. (2001). El valor de educar. Barcelona. Ariel.

Sharp, R. (1988). Conocimiento, ideología y política educativa. Madrid, Akal.

Touraine, A. (1993). Crítica de la modernidad. Madrid. Temas de Hoy.

Wagner, P. (1997). Sociología de la modernidad. Barcelona, Herder. 